\title{
The Application of Analogy Method in the Teaching of "Microcomputer Principle and Interface Technology"
}

\author{
Li Juan, Zhu Jiaxing \\ Department of Engineering, Honghe University, Mengzi 66100, China
}

\begin{abstract}
The course "microcomputer principle and interface technology" is a professional basic courses of the Faculty of science and engineering, but for beginners, the knowledge point is range, abstract and difficult to understand. For beginners to more thoroughly understand the concepts of the course, this article listed some related instances of the application of analogy method in the course. It can make the abstract problems to visualize, enhance learners' learning interest, and improve their learning efficiency.

Index Terms - analogy method, microcomputer principle and interface technology, teaching.
\end{abstract}

\section{Microcomputer principle and interface technology" Introduction}

"Microcomputer Principle and interface technology" is a professional basic course of computer science and technology, communication engineering, electronic information, automation and other professional, Now the course basically is to Intel 8086/8088 CPU microcomputer is described, About PC series microcomputer hardware basic structure and working principle, design and assembly language instruction system, microcomputer interface technology of three parts. In actual teaching process, the working principle of the concept of the course, chips and more multifarious, plus most of knowledge is closely combined with hardware, software and need to have support, content abstract, practicality is strong, Therefore, students generally reflect the course difficult to learn to understand, learn more and more about the end of the course, to feel not fully understand, can not accurately grasp the knowledge points.

From the teaching practice, I found that students of "microcomputer principle and interface technology" is not easy to understand the major are a few reasons: Firstly, in the course related to basic CPU or chips are installed inside the case, although the students have a computer now, but really opened the case study is few, so for them, a stranger chip; Second, even if the students would study chip, also can understand the chip from the appearance of external structure, its internal structure and function for them was a black box, completely empty and abstract, and understanding is much less; Thirdly, both can't see and touch things slowly everyone lost my interest in exploring, nature also unwilling to spend more time understanding; Finally, combined with the scope of this course is very wide, before and after contact closely, often to learn the basis of in front, the back of the application are more a hindrance. A variety of reasons have led directly to "microcomputer principle and interface technology" as most of the students learning difficulties.

\section{The application of analogy method in the actual teaching}

In view of the problem students, I often use the analogy method in the teaching, the part of abstract, difficult to understand and they can see and touch the things in life, find out their similarities, visualize abstract problems, improve students' learning interest in "microcomputer principle and interface technology", to help them better understand the knowledge points in the course.

\section{A. Application one}

$8086 \mathrm{CPU}$ could be divided into four logical sections in main memory, the stack segment is more special, it uses a " The earliest information out of the final " work principle of deposit need to protect data and status information. The concept of stack and working principle for the student, has always been a difficult problem. In order to help the students to understand, I often use the analogy method, the problem of image, vivid. Students have played or seen the tower of Hanoi game, its basic structure is fixed to the bottom of the base, inserted on the stick, circular disc is sheathed on the round rod stacked on the base. It's like a stack segment structure is fixed at the bottom of the top of the stack, the stack, according to the press in how much data and floating. When stacked disc, disc placed first in the bottom, orderly stacked; when the need to remove the disc, is located in the top disc was removed, located at the bottom of the disc and can be taken out, access the stack segment data like disk stacked and removed, the first pressure the data in the end, will be the last out; finally pressed into the data instead of at the top, will be the first out. This is the " The earliest information out of the final " principle.

Using the tower of Hanoi example into the stack, the students not only master knowledge, but also feel the microcomputer principle is not difficult to imagine, but fun. In our life, many similar things, but here the characters into a computer, is the so-called "one size fits all", knowledge originates from life, service life, students are no longer like before often complain about this course is difficult to understand.

\section{B. Application two}

The number of instructions in the source has three possible: immediately, register and memory, it also determines the addressing mode not only, but also very much. Master the addressing mode is not a small problem for beginners, everybody often is not know what course to take. I usually use the analogy of the methods to inspire students: You have to 
contact a foreign friend, you have a lot of choices -- called him to him; Email; direct run to find him. If you want to go to him directly, you can also choose to go by plane, or train, or take a taxi to wait, but no matter what, you can always find him. It's like the operand a variety of possible sources, which originates from the memory and can have a lot of choices. While addressing mode is called looking for operand way. According to the source operand is different, there are a variety of addressing different: from the immediate number called the immediate addressing; from the register called register addressing; from memory is called memory addressing, just from the memory of a slightly more complex, so there are further divided into more detailed. Such an interpretation, the students felt relieved, a feeling so that is what it is.

\section{Application three}

The principle of Microcomputer in this class some concepts seem very shallow, it seems one will see, but with a crash in fact. Such as interrupt interrupt service procedure process, namely the implementation process interrupt service subroutine. Different interrupt request, have different interrupt service routine, need according to the interrupt source to complete the functions, written interrupt service subroutine corresponding into memory, waiting for the interrupt request execution call response. Different sources provide different type of interrupt, CPU interrupt type number automatically according to be multiplied by 4 to calculate the interrupt vector table address, in order to find the interrupt vector that interrupt service subroutine entrance address, to find and execute the interrupt service routine. To explain this process involves a number of new, very similar concept: the interrupt, the interrupt vector table, interrupt service subroutine, the students tend to be at a loss what to do at the beginning, not clear clue, often feel like a maze, wound not come out.The reason, I think mainly lies in the students learning these very similar but the concept is completely different, not able to understand, not to mention the relationship between them clear grasp, resulting in more to study the situation of chaos. To solve this problem, I have a definite object in view to employ metaphor method will be specific, gradually guide the students to clarify ideas, to help them understand the knowledge points.

The students read the university are after more than 10 years of experience of reading, the book structure familiar. Each book is divided into chapters, each chapter has its own page, in order to facilitate access to books, in the beginning will arrange catalog part. The reader through access to directory, can be conveniently or targeted to find several chapters page to read, so quickly into chapters reading. Here each section of the page is like the interrupt vector, which contains all the chapters page directory as the interrupt vector table, the specific content of each chapter is interrupt service subroutine, CPU interrupt service execution process is similar to our access to some chapters process: CPU clear interrupt type number (we determine a goal, find the interrupt vector section) table, get the interrupt vector (to find the number of pages aim chapters from books directory) to perform the interrupt service routine (turn to the target location to read
chapters).Close to the life of this analogy allows students to quickly understand the related concepts, can accurately grasp the relationship between the various concepts, to achieve a multiplier effect.

\section{Summary}

Teaching is the combination of teaching and learning, is an interactive process, the ultimate goal is to hope that students can have the harvest, of course, if the harvest can be fun, we what is there against it? The spirit can make the students relaxed and happy to learn this principle, in the years of "Microcomputer Principle and interface technology" theory in the process of teaching, I always find time to communicate with the students, understand students' learning situation, grasp the knowledge points and difficult problems, timely adjustment according to the actual teaching, try to have a definite object in view, to further improve the effectiveness of teaching. In view of some difficulties exist together, I often use the analogy method, the abstract, boring questions with more life examples to compare, make specific, vivid, convenient for the students to understand and master. In view of some difficulties in the course, I have done experiments: in the course of the premise of the same, a class of students using the analogy method of teaching, another class is the general teaching method, explain again the knowledge points for the students to do on-site practice, specific statistics are listed in the following table:

TABLE I Result Form analogy teaching and pedagogy of teaching

\begin{tabular}{|c|l|c|c|c|}
\hline & Knowledge & $\begin{array}{c}8086 \text { Storage } \\
\text { System }\end{array}$ & $\begin{array}{c}\text { Addressing } \\
\text { Modes }\end{array}$ & $\begin{array}{c}\text { Interrupt } \\
\text { Service }\end{array}$ \\
\hline \multirow{4}{*}{$\begin{array}{c}\text { Analogy } \\
\text { Teaching }\end{array}$} & Count & 60 & 60 & 60 \\
\cline { 2 - 5 } & Correct & 41 & 50 & 36 \\
\cline { 2 - 5 } & False & 19 & 10 & 24 \\
\cline { 2 - 5 } & Correct Rate & $68 \%$ & $83 \%$ & $60 \%$ \\
\hline \multirow{4}{*}{$\begin{array}{c}\text { General } \\
\text { Teaching }\end{array}$} & Count & 60 & 60 & 60 \\
\cline { 2 - 5 } & Correct & 29 & 33 & 16 \\
\cline { 2 - 5 } & False & 31 & 27 & 44 \\
\cline { 2 - 5 } & Correct Rate & $48 \%$ & $55 \%$ & $27 \%$ \\
\hline
\end{tabular}

From the analysis of the statistics, from the perspective of master degree, analogy teaching can let the students accept, understand and grasp the problem more than ordinary method of teaching; from the time perspective, metaphor and significantly improve the students learning efficiency. Metaphor method in practical teaching and achieved good teaching effect.

\section{References}

[1] Dai Meie,Shi Jiaquan. Micro computer technology and application (Third Edition) . Beijing: Tsinghua University press,.2004.

[2] Zhou Mingde. Principle and application of microcomputer system (Fifth Edition) . Beijing: Tsinghua University press,.2007.

[3] Zhu Xiaohua. Microcomputer principle and Interface Technology (Second Edition) . Beijing: Publishing House of electronics industry.2008.

[4] Ma Chunyan. Microcomputer principle and Interface Technology (32 machine based on .)Beijing Electronics Industry Press,.2008. 